\title{
Emotion regulation Strategies in Teaching Profession Case Study of an International Primary School Teacher in Jakarta, Indonesia
}

\author{
Dani Surya Lee \\ Faculty of Education, Southwest University, Chongqing 400715, People's Republic of China
}

\begin{abstract}
Emotion is a driving force behind almost everything teachers do, even more than ratio at times. Teachers are not robot. The emotions they feel are real and influential toward their effectiveness. They deal daily with other individuals, all with their own demands and different opinions, personalities and abilities, hence, conflicts cannot be avoided and stress is formed. Stress causes teachers to experience negative emotions; which, if allowed to linger, may cause harm to the teachers themselves as well as the individuals in which the teachers interact with. Emotion regulation methods, guided by emotional health, are vital for dealing with the stress that has emerged from various situations and problems in the workplace. By conducting a research interview with a biology teacher of a known international school in Jakarta as a study case, this paper will probe the cognitive process of choosing and employing emotion regulation methods. It will discuss the emotion regulation methods used in dealing with negative emotions and briefly discuss the importance of emotional health for teachers when dealing with workrelated stress and demands.
\end{abstract}

Keywords: teacher's emotion; emotion regulation strategies; emotion in teaching

DOI: $10.7176 / \mathrm{JEP} / 10-9-21$

Publication date:March $31^{\text {st }} 2019$

\section{Introduction}

Hargreaves's (1998) in The Emotional Practice of Teaching wrote: "Teaching is an emotional practice, which depends on emotional understanding, involves immense amounts of emotional labor, and is integrally bound up with the purposes of teaching and schooling. Together, these precepts present a compelling case for conceiving the emotions as a central rather than an ephemeral part of teaching and schooling, and therefore as phenomena worthy of much more explicit attention in educational policy and reform."

Emotion is a driving force behind almost everything we do, even more than ratio at times. This is even truer for teachers. Teachers are not robot. Emotions dictate teachers' motivation and drive when preparing, teaching and evaluating the lessons, as well as when facing vulnerability due to problems that aren't within their control. Negative emotions that teachers feel will influence those around him, most often in a negative way. If these kinds of emotions are prolonged, it may cause harm for the teachers' health, careers and future, as well as to those affected by the educational process - mostly the students in this case. On the other hand, emotions can also increase teachers' motivation and drive to 'walk the extra mile' in doing their responsibilities as educators.

Same problems or demands may cause different reactions to different people. We must have all seen this in our own workplaces. The weight of the problem is of course the main reason for certain reactions, but there is also an internal factor which has an immense contribution to this, and that is the emotional health. A well-maintained emotional health gives teachers the ability to deal with stress and negative emotions appropriately by allowing them to choose the correct emotion regulation method to deal with the situations at hand.

Unfortunately, teachers' emotional health is a topic that hasn't receive the necessary attention it should. This paper explores, to a certain degree, the emotional thought processes that has actually been conducted by an educator in his workplace, and discussed the emotion regulation strategies that he employed in order to deal with the negative emotions experienced.

\section{Literature Review}

\subsection{The Concept of Emotional Health and Emotional Intelligence in the Teaching Profession}

In a nutshell, emotional health is simply the ability to express our emotions in an appropriate way (Philpott, 2017). Emotion itself encompasses a broad area of our individual self and has almost uncountable elements. Emotions fear, terror, anger, rage, joy, ecstasy, sadness, grief, acceptance, trust, disgust, loathing, anticipation, surprise, etc. - are mental states consist of complex multi-componential processes which play a vital role in our lives, arise when we face a situation relevant to us, shaping everything from what we see to how we respond, including possible physiological changes, and, therefore serve as an adaptive role in helping us to deal with key survival issues posed by our environment (Plutchik, 1980; Gross, 2008; Koestler's, 1967). In other words, if emotions are the responses that our mind gives out when facing certain situations which include changes in both the psychological and physiological aspects, and influence our next possible actions, then emotional health is the degree of how adept 
our psychological states are to be able to respond well to the those changes.

Emotional Intelligence, or EI for short, is hugely linked to emotional health. It is the ability or skill to recognize and manage one's emotions and the emotions of others, reflected in personal coping and self-regulation which are governed by mental and emotional health (Seal et al., 2009; Vesely et al., 2013). EI is also may be defined as the ability to regulate one's own emotion state to appropriately handle the mental stimuli raised by the situations at hand in order to manage one's own emotions as well as the emotions of others.

There are two schools popular in the subject of EI, one focuses on the Emotional Ability and the other one focuses on the Emotional Competence (cited in Seal et al., 2009). EI school of Emotional Ability observes the following four aspects and measures them using highly normed quantitative methods: Perceiving emotions, facilitating thought, understanding emotions, and emotional management (Mayer, Caruso, \& Salovey, 2016). Meanwhile, the EI school of Emotional Competence combines aspects of intelligence and emotion to determine the actual or perceived frequency of specific behaviors, and measures how frequently individual competencies are demonstrated within four broad emotional clusters: Self-awareness, self-management, social awareness and relationship management (Schutte, 1998). Combining the two schools, I've summarized the following elements to be observed in order to ascertain a person's Emotional Intelligence:

1. Sensing emotions, the ability or awareness to notice one's own as well as others' change of emotions.

2. Comprehending emotions, the ability to understand the emotions currently felt of showed (where it originated from, its meaning and possible influence or consequences).

3. Regulating emotions, the ability to process and regulate these emotions.

4. Evaluating emotions, assessing the concrete result than is born from managing these emotions by certain emotion regulation methods, whether the appropriate inner and outer response, as well as the desired results, are obtained or not.

I can conclude that EI can act as two things: First, as the foundation on which emotional health can be built; and, second, as a standard on which a degree of emotional health related to an individual's professional life can be understood. I believe that through a deeper understanding of a person's EI reflected in his/her actions and experience, we can, to some degree, probe his/her state of emotional health.. Please notice that I use the term Emotional Intelligence (EI) instead of Emotional Quotient (EQ) to describe a person's innate ability to manage emotions. I would not try to measure the EQ of any individuals discussed here.

Because this paper concentrates on the usage of emotion regulation strategy, the analysis will be focused on the third step of EI, regulating emotions.

\subsection{Emotion Regulation Strategies in the Teaching Profession}

Stress is an ongoing transaction between the environmental demands and a person's resources, with negative psychological strain resulting from an imbalance between these demands and resources (cited in Neil et al., 2011). Individuals within the teaching profession continue to be vulnerable to high levels of occupational stress, which creates increased emotional demands leading to exhaustion and burnout, decreased job satisfaction, mental health problems, and ultimately leaving the profession (cited by Vesely et al., 2013; Hargreaves, 1998). Stress is not an emotion in itself, but a mental state that develops when limited resources meet strenuous occupational demands. It is an element that influences a teacher's emotional labor, among other things.

Emotional labor is the process of managing internal feelings and external expressions to follow publicly desired facial and bodily display (Grandey, 2000; Hochschild, A. R., 2012). As it is commonly known, it is required for teachers to be role models for those whom they teach. It is demanded of them to manage their emotions in order to please their audiences (including students and other stakeholders such as parents and principals). It is basically impossible for teachers to elude the stress that occurs as a result of the emotional labor that teachers must engage day to day in their profession. Therefore, appropriate strategies in managing emotions is crucial for teachers to achieve effective teaching (cited in Lee \& Vlack, 2017). Higher levels of EI can mediate stress escalation and improve its management (Vesely et al., 2013). Stress and the emotional labor stress causes may have a negative impact on a teacher's efficacy, but a high level of EI may help manage this problem.

Hargreaves's (1998) mentioned that teaching is an emotional practice. It activates, affects and expresses teachers' own feelings and the others with whom teachers work and form relationships. Teaching involves emotional understanding, which helps us to recognize and understand if the emotions we see or feel are either justified or misplaced in a certain context, and helps us to respond accordingly as we see fit. Teaching involves immense amount of emotional labor. It exposes teachers, making them vulnerable when the work conditions and occupational demands make it hard for them to do their 'emotion work' properly. In addition, teachers' emotions are inseparable from their moral purposes and their ability to achieve those purposes. When purposes cannot be achieved, anxiety, frustration, anger, guilt and other negative emotions may erupt as the consequence.

However, the definition of emotional labor is somewhat simple and too general in nature. To rectify this, the term emotion regulation represents a broader concept of behaviors compared to emotional labor, as it includes all of the efforts to increase, maintain, or decrease one or more components of an emotion (Côté, 2005; Gross, 1999). 
The usage of the word 'regulation' itself may give a clearer understanding than 'labor'. Emotion regulation may give a more comprehensive understanding and methods to manage emotions compared to emotional labor. In this paper, the term emotional labor will refer to the pressure for teachers to put on a pleasing display of emotion, while the term emotion regulation will refer to the methods used to deal or handle various emotions that emerge due to internal and external triggers.

Based on the work of Gross (2008), the following five points are places in time which emotion regulation may occur: Selection of the situation, modification of the situation, deployment of attention, change of cognitions and modulation of responses. Situation selection involves actions to facilitate a situation expected to give rise to the preferable emotions. Situation modification is a response to stressful events and difficulties by concentrating efforts on modifying the situation. Attentional deployment refers to redirecting attention within a given situation through distraction, concentration and rumination. Cognitive change refers to altering one's appraisal(s) on a certain situation or the capacity to manage the demands. Response modulation occurs late in time and has a relatively direct manner of suppressing unwanted emotions.

There are two strategies in regulating emotions: surface acting and deep acting. Surface acting focuses on modifying emotional expressions, which includes faking unfelt emotions and hiding felt emotions, while deep acting concentrates on regulating or altering internal feelings to really experience the desired emotion. In general, surface acting (emotional expressions modification) shows positive relationships with negative emotions, such as frustration, while deep acting (internal feelings modification) shows positive relationship with positive emotions, such as enjoyment and pride (Grandey, 2000; Hochschild, A. R., 2012; Lee \& Vlack, 2017; Côté, 2005).

In practice, deep acting concerns with the manipulation of components of emotions before they are fully under way. As such, deep acting changes both the internal experience and the public display of emotion. Appraising a situation purposefully to create both the internal experience and the public display of a certain emotion is a practice of deep acting. Surface acting concerns with the manipulation of components of emotion once the emotion is fully under way. As such, surface acting changes the public display but not the internal experience of emotion. Hiding true emotions felt by displaying a more preferable display of other emotions is a practice of surface acting. The latter is somewhat similar to Gross' (2008) response modulation. Another set of emotion regulation that complements deep acting and surface acting is emotion amplification and emotion suppression (Côté, 2005). Emotion amplification consists of initiating or enhancing public displays of emotion. For example, sales clerks may exert effort to enhance their public displays of enthusiasm. Emotion suppression consists of reducing or eliminating public displays of emotion. It is important to note that emotion suppression generally does not entirely hide the public display of emotion.

\section{Research Framework and Methodology}

From the literature review, we can conclude that effective teachers draw from their adequate emotional health reserves when trying to employ the correct emotion regulation methods in handling negative emotions in workplace. These emotional health reserves are defined by the observable elements of Emotional Intelligence (EI). Through questions based on the observational points of EI (i.e.: noticing emotional changes, comprehending emotions, regulating emotions and the subsequent results), this paper will probe how the research subject dealt with negative emotions in the workplace. This paper will discuss the overall process of emotion regulation as a strategy to manage negative emotions in teachers' workplace based on real-life experience of a teacher. This paper would answer the following research question: What are the emotion regulation methods used in dealing with negative emotions?

The subject of study in this research is Carl. He is in his late twenties, belongs to one of Indonesia's wellknown native ethnic group and currently a graduate student in a university here in China. He has a bachelor in teaching biology and graduated from the Lighthouse International University in Indonesia, a university with an international curriculum from the USA. He had worked as a teacher in Lighthouse International School, an international school in Indonesia, for 6 years before coming to China to pursue further education. He taught science and biology in the sixth to twelfth grade during his occupational period, and had also taken the responsibility as a homeroom teacher. I chose him for the case study because we have a good relationship and therefore it was easier for him to be opened with me. A personal interview was conducted between Carl and I, and the result was used to establish a narrative data that could be analyzed and summarized. I need to note that the name 'Carl', as well as any name of organization or school mentioned here are pseudonyms.

The results of the interview will be discussed in section 4 below, while the discussion on findings will be discussed in section 5 .

\section{Interview Results}

I need to first clarify some terminologies that may come up below in the result of the interview section. 'Students' refers to the students he directly taught; 'parents' refers to the parents of the students he taught; 'teachers' refer to the teaching staff, including him; 'colleagues' refers to other teachers in the teaching staff; 'the school' refers to 
the organization (management) of the school where he worked at; and 'supervisor(s)'

Carl stated that emotional health is very important for teachers, whether it's in the classroom practice of teaching phase, in the lesson preparation phase, or in the student assessment phase. A teacher's responsibility is not only to transfer knowledge, but also to educate good moral values and to shape a better behavior in the students. A teacher's emotional health will be reflected in the teaching process. According to his own personal experience, whenever he undergoes negative emotions ${ }^{1}$, his teaching performance was also negatively affected. In addition, the students, to some extent, could also see this emotion although they didn't know the detail or cause. Experiencing negative emotions in the lesson preparation phase also has negative effects by lowering the teacher's motivation to do the job properly and making the task at hand merely a formality ${ }^{2}$. In the assessment phase, Carl stated that subjectivity impacts student assessment greatly, and emotional health influence subjectivity, which in turn will influence how teachers see their students and their development.

We will now discuss the stressors that Carl experienced. Carl quoted a sentence from a literature he once read:

"When you have a high performing teacher, do not let him be a robot, because

he overworks, yet underappreciated." (Carl, personal Interview, December 20,

2017)

The teachers in Carl's school, including himself, have so many things to do, yet sometimes do not receive the proper appreciation from the school. It is not about the salary or benefits, but simply the lack of emotional appreciation or support, as well as professional development. According to Carl, the teachers kept on doing their best, but yet it was considered only as part of their obligations and hence were given no attention. The need for quality training to promote their professional development was also somewhat ignored by the school. Carl argued that without the input from his supervisors, along with the appropriate practical trainings from professional trainers, he would only be going in circles, doing the same routine over and over again. There were trainings, but because the teachers in that school were not included in the curriculum development of those trainings, they were lacking the actual content necessary to promote professional development.

Personal issues, according to Carl's experience, was not much of an issue. His life revolved around his occupation. The emotional distress that came from his family, social or personal life was insignificant and only had some minor influence on his work. Most negative triggers for stress, he added, were originated from professional issues, his work life. Carl set an example, he defined himself as someone who was keen to pursue something better, he was critical toward issues and situations that could be improved. So if there were issues that were not optimally managed, ones that he couldn't do anything about - other than to observe and to give suggestions only to be ignored in the end -, he would experience stress. To be clear, the occupational stress example given above was due to the unsatisfaction he felt from the school organization, not from factors such as the students themselves or the workload.

Carl shared that during times of stress, the most common emotions he felt were anger and disappointment. He would still try to give his best in terms of suggestions and performance, but if continued, the peak would be apathy. He would do what was required of him, but he would not give any insightful feedback. In his own words:

"That's fine. I will work for you, but I will work as a robot. I will do what you

want, but that's it. You will not get the best of me." (Carl, personal Interview,

December 20, 2017)

In the interview, he stated that he bypassed 'frustrations' and went straight to 'apathy'. The attitude he had shown through his quoted words above, he argued, was a mechanism for him to avoid frustration.

Sharing another experience of being apathetic, in the fifth year of his career he felt like he had enough. There were so many things to do, so many events and responsibilities, but he only treated them as check-lists. He also considered suggestions he gave to the school as mere formalities, as he reckoned that it was not within his power to actually realize those suggestions. Another example, when there were trainings, he only did them as formalities. One of the reason was because the teaching staffs were not asked for feedbacks and suggestions before and after the trainings. They were not included in the decision-making process concerning the content and materials of the trainings, and therefore, he argued, that the trainings were of little relevance to their current situations and necessities.

I will now discuss the emotions that Carl stated to have felt and the subsequent reactions.

"Whenever I faced anger, this was what got me back to the right path, I looked

at my students... For the sake of the students, that's okay... Let's do our best."

(Carl, personal Interview, December 20, 2017)

Anger. Carl shared that the emotion of anger he experienced was mostly between him and the school. In the past, he sometimes released those anger during teaching time, but then he felt remorse. He looked at his students, and he reflected to himself that this, being angry to them or carrying negative emotions, would have a negative

\footnotetext{
${ }^{1}$ Exact words: Feeling emotionally unstable.

${ }^{2}$ Exact words: Do it for granted; only as check-points.
} 
impact on his teaching, which would impact the students' learning, and hence impact their future. So in the last year of his service, before he came to China to continue his education, he focused on his students. He looked at the future of the students to suppress his own emotions. In addition, there was anger triggered by the students themselves, for instance, due to a student's inability to solve a problem, or a problematic student. Carl would sometimes felt stressed because he cared too much about a certain student with a problem, but it did not influence him greatly. When he started to feel the stress, his ratio would take over and divert his attention to the rest of the students who also needed his attention, then he would manage the class to fix the problem as well as possible.

For example, once there were a group of foreign students learning in his class. He knew that they were cheating he found a book in the toilet which some of the students went to during the exam - so he talked personally to one of them and asked why they cheated. It turned out that the demands from their parents were extremely high, especially concerning grades. So Carl said to him the following:

"Your grade doesn't matter for me... you are more important for me than your grade. And when you start cheating... you will be addicted to it... Even though you are smart enough to do your exam, when you know that you can cheat, you will lose the effort... that character will turn into corruption in the future..." (Carl, personal Interview, December 20, 2017)

Afterward, surprisingly enough, that student shared this experience to his fellow classmates, and then five other students came to Carl and admitted that they have also cheated. They came to a solution together that they would do another test to make up for this one. The test was held several days after.

"I just tried to let it go... I became used to it, anyway..." (Carl, personal Interview, December 20, 2017)

Disappointment. In his third and fourth year, he experienced a lot of anger toward his supervisors, the curriculum coordinator for instance, which has led to disappointment. But after that period, he simply let those emotions go $^{1}$. His colleagues testified to often see him sighing while walking in the hallway. During those times he tried activities such as traveling and hiking to take his mind of those emotions. He also had a lot of activities with his students outside of his teaching time, such as having meals together and building relationships. These activities had helped to distract him from the stress he was experiencing.

"Okay, let's not make a fuss... let's listen to what she has to say and let her be gone... I became a 'yes-man'... a robot." (Carl, personal Interview, December 20, 2017)

Apathy. Carl's experience with apathy was simply acceptance. He would do what was instructed and what was needed of him from the school, but he would not give the extra effort for those instructions or do things better than what was required of him to do (although he stated he could do them better). According to him, many times, the policy given by the school hampered the learning process itself. The policy was only for the sake of policy and did not have practical use for the learning experience.

Concerning other stakeholders, Carl shared that his colleagues were friendly and supportive of each other, so there was no tension between them. The parents, some of them were traditional in their understanding of modern education, and therefore at times might challenge his teaching method (e.g. wanted him to give more homework). He usually met with them, built rapport, then gave some insights. He tried to solve the problem - the cause of the stress - that happened in relation to the students' parents, but if this didn't work, he would go to his superior, academic advisor, explained the situations, and asked her to give him advice or to help deal with the problem. The stress concerning the parents, however, were insignificant.

Finally, Carl stated that he has found it really difficult to fake his emotions. Although he would try to hide negative emotions sometimes, due to the Asian culture in which displaying strong emotions may be considered disrespectful, he would prefer either to fix the problem or to consciously 'employ indifference'. He added that going through the emotional turmoil in his career, he realized that he still had difficulties in handling certain emotions. At times he felt helpless facing his inability to do anything significant to modify an undesirable situation. Carl emphasized that his motivation as an educator, although was challenged, still remained unchanged and was kept from being diminished by the stress he had undergone during the six years of his career. He stated that he would always try to be a better teacher, however, he commented that he would probably work for a different organization.

To end the interview, Carl gave an insight to the topic of handling emotion and commented the following about himself:

"At the end of the day, it was I who control my emotion, and I should not let others control it... I should not make important decisions when I am emotionally unstable. At the same time, I should not take others' decisions

\footnotetext{
${ }^{1}$ This concur with Carl's statement above concerning the step of emotion he felt: Anger, then disappointment, then apathy. The discussion on apathy is discussed in the next paragraph.
} 
seriously when they are emotional... I am a life-long learner, and I will share that learning process to others, so that others and I can be better..." (Carl, personal interview, December 20, 2017)

\section{Analysis and Discussion}

The teaching profession is demanding. It is impossible for teachers to elude the stress which occurs as a result of the emotional labor that teachers must engage day to day in their profession, in particular, showing a pleasing façade under the pressure of demands from the school, parents, leaders, students, and even the teachers themselves. Taking Carl's stories into account, occupational stress can trigger the development of negative emotions of anger, disappointment, leading up to apathy. The last one is especially dangerous as it can make teachers indifferent to all kinds of issues, from the needs of the students to their motivation to give the best effort in doing their responsibility.

Nevertheless, I have to argue that in a small dosage, apathy can be employed positively. Frustration, as it is generally known, is one of the main reason for teachers' burnout. Carl stated that he bypassed 'frustrations' by directly taking on 'apathy'. It was a mechanism for him to avoid frustration. In other words, it is healthy for him to be apathetic toward certain stress triggers. It is not healthy, however, if the emotion is allowed to linger, as it will create indifference. Apathy can only be used in a brief moment. Teachers need emotional health to transform this 'apathy' into 'acceptance', or to be more specific: Strategic selective acceptance, a behavior of acceptance toward things that are out of our control in order to avoid frustration and strengthen focus toward more important things that are in our ability to act upon.

A high EI facilitates good emotional health, as individuals' with higher EI are able to have better emotion regulations (Vesely et al., 2013). Still, negative emotions are related to teachers' personal growth, and does not always have a negative impact if monitored, targeted and restructured correctly to boost motivation, as well as improving concentration and effort (Chen, 2016; Neil et al., 2011).

It's fortunate that Carl has never experienced burnout as the result of stress. Yet it was implied in the interview, especially in the last part, that the reason his self-esteem, motivation and future perspective as a teacher remained intact was because he had a good dosage of emotional health to help him focus to the important things - in this case, his students - and to help him divert his attention to the emotional distraction itself.

The following discussion will base the analysis on works by Grandey (2000), Côté (2005), Gross (2008), Hochschild, A. R. (2012) and Lee and Vlack (2017).

\subsection{In facing 'anger'}

From the result of the interview, we can see that anger is the most pronounced and the first of negative emotions that Carl felt. Carl seemed to employ different methods to deal with anger from different stressors.

In dealing with stressors from school, he used attentional deployment by redirecting his attention to the students. He stated that in the past, he sometimes released the anger he felt due to this stressor during teaching time, but then he felt remorse. He realized that being angry with the students or carrying negative emotions due to stress from other sources would have a negative impact on his teaching. Therefore he used the students as a source of distraction, concentrating on their education.

In dealing with stressors from the students, he used different kinds of regulation method. He used cognitive change when he focused too much on certain problematic students, which he said has made him disregard the need of the rest of the class. Carl stated that his ratio would take over and make him realize that the other students also needed him, and hence he could not afford to 'lose his cool'. He then used situation modification to fix the problem or to deal with the students. An example was when dealing with the students he knew to have cheated in the exam, his effort was directed toward speaking to one of the cheating students, to make the student realized the importance of integrity which finally made the student and his friends who cheated to amend their mistakes.

We can see that attentional deployment, cognitive change and situation modification used here are parts of the emotion regulation method of deep acting. When Carl feels anger, he would concentrate on regulating or altering that negative emotion to feel the emotions he preferred instead. We can see here too, however, that he employed emotion suppression by reducing or eliminating public displays of anger in front of the students, which I believe to have actually facilitated him in conducting his cognitive process of attentional deployment, cognitive change and situation modification. He first suppressed the anger, and then used the cognitive emotion regulation methods to deal with the feelings internally.

\subsection{In facing 'disappointment'}

Carl stated that in his third and fourth year he experienced a lot of anger toward his supervisors which has led to disappointment. We can see here an example of how prolonged anger can lead to disappointment if the root cause, i.e. the cause of the problem, is kept unsolved.

To deal with this disappointment, Carl tried activities such as traveling and hiking, as well as activities with 
his students outside of his teaching time to take his mind of this negative emotion. This shows that he employed attentional deployment by redirecting attention to other activities; he didn't deal with the problem as he did with the students that cheated, for example, because it was out of his control. Hence, he could only distract himself by doing activities that could take his mind of the problem.

Carl also stated that his colleagues said that they often saw him sighing while walking in the hallway. This is a sign of acceptance, in a sense that there is nothing he could really do about it. This signifies cognitive change and response modulation when he appraised that the situation was out of his hands, it was not in his capacity to modify the situation, and then simply suppress the disappointment.

We can see that deep acting was employed when Carl used attentional deployment to deal with disappointment, and surface acting when response modulation was used. However, the use of cognitive change, which is actually a type of deep acting, had led to the response modulation in surface acting. This shows that deep acting can lead to surface acting if a problem keeps on presenting itself due to not being resolved.

\subsection{In facing 'apathy'}

In the long run, as Carl has stated, his negative emotions had turned into apathy. This emotion is actually a 'result' instead of a 'factor' like anger or disappointment. The apathy in itself was a response modulation that occurred late in the process of Carl feeling negative emotions and processing them. It was an emotion suppression technique, his way of surface acting to suppress other emotions that he felt might influence his teaching ability. Keep in mind that the apathy he felt was in relation to some organizational stressors, such as the school policy, dissatisfaction with his supervisor, etc.

We can summarize that when Carl faced anger and the root of the problem was not solved, in the long run, disappointment would occur and apathy would be the final resort as response modulation was employed excessively in order to deal with problems that were not in his control. This sort of 'indifference' was employed as an effort to reduce the influence of the two previous negative emotions on his teaching efficacy. This was an example of strategic selective acceptance, an effort to reduce the influence of negative emotions on performance by accepting certain situations of facts that are out of our control that I have mentioned earlier.

\section{Conclusion}

From Carl's experience, we can answer the research question that the emotion regulation methods used in dealing with negative emotions include situation modification, attentional deployment, cognitive change, and response modulation, the former three represents deep acting, while the last one represents surface acting, all of them, however, required emotion suppression.

The emotion regulation method of situation selection didn't show any sign on being employed as it needs to involve actions to facilitate a situation, while the problems which led to the emotional apathy were caused by factors outside of Carl's control. In another word, he would always be exposed to that negative feeling unless he exit that environment. This may be the case, however, as he stated that he would probably work as a teacher in another organization in the future, which signifies that the situation selection method will be employed in the future.

I can conclude that emotional health is crucial in determining teachers' efficacy and their ability in handling negative emotions due to stress in the workplace. It directly influences the level of effort teachers will give in doing their responsibilities as an educator. Also, negative emotions can be very easily recognized and will impact other people around the teachers themselves. Therefore it is important for them to show professionalism by regulating their emotions using the appropriate emotion regulations method.

The negative emotions that teachers feel, such as anger or disappointment, etc., will lead to apathy. Apathy will lead to indifference and ignorance, resulting in the decrease of motivation and in the overall effectiveness. In this kind of time, teachers need to have a healthy dosage of emotional health to help them to manage these emotions and create strategic selective acceptance to release the issues they face are out of their hands while increasing the drive to handle the issues that are within their capacity to do.

When employing an emotion regulation method, teachers should first consider the repercussion that may follow. Surface acting may be employed in order to give the emotion a 'quick fix', but deep acting, if possible to do, is always better. When experiencing negative emotions, we must always refocus our attention back to the main reason behind our motivation in doing the task. Carl refocused his attention to his students. When he did this he realized that his reason, i.e. the students' education, was immensely important. This understanding put him into a new perspective. It magnified his motivation and drive, and diminished the severity of his situations, making them doable.

Finally, I would like to propose the importance of emotional health for teachers when dealing with workrelated stress and demands as a threefold factor: First, it promotes strategic selective acceptance; second, it facilitates the creation of pacifying diversions from stress; and third, it shapes unwanted experience or negative emotions originated from stress, to become medium for personal and professional growth. 


\section{Reference}

Chen, J. J. (2016). Understanding teacher emotions - The development of a teacher emotion inventory. Teaching and Teacher Education, 55, 68-77.

Côté, S. (2005). A social interaction model of the effects of emotion regulation on work strain. Academy of Management Review, 30, 509-530.

Lee, M. \& Vlack, S. V. (2017). Teachers' emotional labour, discrete emotions, and classroom management selfefficacy. Educational Psychology 2017. DOI: 10.1080/01443410.2017.1399199

Grandey, A. A. (2000). Emotion regulation in the workplace: A new way to conceptualize emotional labor. Journal of Occupational Health Psychology, 5, 95-110.

Hochschild, A. R. (2012). The managed heart: Commercialization of human feeling 3rd edition. Berkeley: University of California Press.

Gross, J. J. (1999). Emotion and emotion regulation. In L. A. Pervin \& O. P. John (Eds.), Handbook of personality: Theory and research 2nd ed. (pp: 525-552). New York: Guilford Press.

Gross, J. J. (2008). Emotion and emotion regulation: Personality processes and individual differences. In O. P. John, R. W. Robins, \& L. A. Pervin (Eds.), Handbook of personality: Theory and research 3rd ed. (pp. 701724). London: The Guilford Press.

Schutte, N.S., Malouff, J.M., Hall, L.E., Haggerty, D.J., Cooper, J.T., Golden, C.J. \& Dornheim, L. (1998). Development and validation of a measure of emotional intelligence. Personality and Individual Differences, 25, 167-177.

Hargreaves, A. (1998). The emotional practice of teaching. Teaching and Teacher Education, 14(8), 835-854.

Hargreaves, A. \& Earl, L. (2002). Perspectives on alternative assessment reform. American Educational Research Journal, 39, 69-95.

Neil, R., Hanton, S., Mellalieu, S. D., \& Fletcher, D. (2011). Competition stress and emotions in sport performers: The role of further appraisals. Psychology of Sport and Exercise, 12, 460-470.

Mayer, J. D., Caruso, D. R., \& Salovey, P. (2016). The Ability Model of Emotional Intelligence: Principles and Updates. Emotion Review, 8, 290-300.

Philpott, N. (2017, November 23). Mental health vs. emotional health - are they related? [Blog Post]. Retrieved from http://www.selfgrowth.com/articles/mental-health-vs-emotional-health-are-they-related.

Plutchik, R. (1980). A general psychoevolutionary theory of emotion. In R. Plutchik \& H. Kellerman (Eds.), Emotion - theory, research, and experience vol. 1: Theories of emotions (pp. 3-33). New York: Academic Press.

Seal, C. R., Sass, M. D., Bailey, J. R., Liao-Troth, M. (2009). Integrating the emotional intelligence construct: the relationship between emotional ability and emotional competence. Organization Management Journal, 6, 204-214.

Vesely, A. K., Saklofske, D., H., \& Leschied, A. D. W. (2013). Teachers - the vital resource: The contribution of emotional intelligence to teacher efficacy and well-being. Canadian Journal of School Psychology, 28, 7189. 